\title{
(BIOLOGICAL) LIFE: THE PEDAGOGY OF AN ARCHITECTURAL CONCEPT
}

\author{
STEPHEN LOO \\ Louis Laybourne Smith School of Architecture and Design \\ University of South Australia \\ City West Campus, North Terrace, Adelaide, SA 5000, Australia
}

stephen.loo@unisa.edu.au

\begin{abstract}
This paper analyses the techniques and technologies mobilized under the imprimatur of biological life in architectural production beyond their manifestations as (bio)mimetic processes. The arguments do not take 'life' as a priori to architectural thinking, but as immanent to each enactment of technique or application of technology within the biological paradigm. Using the work of Roger Caillois on pyschasthenia as the collapse of space between an organism and its milieu, the analysis avoids elevating biological life to a transcendent concept. Biological life in architecture instigates the pragmatic concern for whether a philosophical or scientific concept works, or matters, regardless of whether it fits within an ontology or metaphysics. Thus, architectural production using biological life subscribes to a Deleuzo-Guattarian "pedagogy of a concept" - the creation of perceptual and affective habits that are self-jeopardising and highly idiosyncratic to ensure further concept formation.
\end{abstract}

Keywords: Biological life, biomimicry, immanence, pedagogy of the concept.

\section{Introduction}

Concepts of emergence and self-organisation in architectural practice, whose foundations lay in the concept of 'life', herald a return of the biological paradigm to architecture. Current transfers of the biological to the architectural stand more as technical and technological concerns - that is, concerns of process and method - than straightforwardly formal ones. In this paper I argue that it is more productive to see biological life in contemporary architecture, especially in the field of experimental digital architecture or what Michael Hensel and others have called "morphogenetic design", as not a priori to architectural thinking, but rather as a force effectuated at each enactment of particular techniques and technologies. The potential of the biological paradigm for architecture is much more than its manifestation as mimetic formal or methodological processes because in the enactment of the biological is the very possibility of differential conceptions of life. Life in this case becomes more of a contingent but generic quality rather than a predetermined condition; which moves the notions of transfers of technique, and transformations of the technological, away from instrumentalist definitions. Life is the immanence of biological techniques and technologies to its transfers and transformations in architecture. 
The aim of this paper therefore is not to find new potentials for the biological paradigm, whether from science and philosophy, to be used in architecture, nor will it outline how architecture is appropriating the biological, or why we are seeing a resurgence of this practice. The paper argues that in the current biological paradigm, the concept of life does not arrive in architecture from the outside through interdisciplinary transfer, nor is it intrinsically internal to the biological. Life as a concept in architecture can be cultivated (as in habits), and remains divergent (as in mood or atmosphere) without relying upon an a priori object.

\section{Searching for and identifying life}

The appeal of a biological paradigm in architecture is, in short, to find relations between the material world and the possibility of its own generation, development and therefore sustainability. This model of the world relinquishes the human being as progenitor and creative source of material transformation towards cultural production. In corollary, the biological paradigm instates the non-human world with an interior, perhaps primordial, creative force given by a certain consistency or organization of the beings within it. What this means is techniques and technologies arising from a biological paradigm in a cultural production such as architecture become the search for life within categories of materiality, systems and their relations, outside the imprimatur of the category called the human being.

The process of identifying life in the material world - to ascertain if something has the quality of being alive or not - whether as biological organisms (animal or vegetative) or biochemically synthetic forms (naturally occurring or otherwise), adheres to strict criteria. The main criterion is the capacity for self-organisation and dynamics. For example, in discussing the literal transfer of the biological paradigm into architecture, Michael Hensel, quoting Hungarian chemical engineer and biologist Tibor Gánti, states that the criteria for life identify the ability of the organism or system to enact transformations of states and material (for example metabolism), communicate and transfer information, control internal states in relation to the external environment, development and reproduction, and finally mortality (19-20).

The ground for these criteria is given by two metaphysical assumptions. Firstly, the existence of a frame which partitions the inside and outside that establishes an architectonic unity. And secondly, the registration of life within this unity relies upon the enactment of a visual difference from the unity, taking the form of a 'response'.

Architecture has since the beginning of Western thought provided philosophy with the ground for the operation of metaphysics and culture. Architecture in descriptions of itself sets up relations between inside and outside, above and below, and space and boundary; relations which philosophy protects as incontrovertible in order to do its work, and in doing so establishes what Mark Wigley calls an "epistemological contract" with architecture (5). More importantly, philosophy's debt to the architectural already always defines the how the life can appear through the definition of what is human. Architecture in its history has played a role in partitioning human life as outside an undifferentiated interior biological life. In Aristotle, zoé or bare life as the unqualified life of natural (or domestic) reproduction that does not subscribe to constituted sovereignty, is differentiated from the bios as life exteriorly qualified by the law/language towards a usefulness within a political community (Agamben 7).

Within the biological paradigm in architecture, life emerges as a functionalist explanation. In order that human life can be partitioned from biological life, the latter must be defined in such a way that it is available as a unit of differentiation and manipulation. The definition of biological life literally arrives from the possibility of 'containment', that is, a differentiation between interiority and exteriority. At its most elementary scale containment is given by the unified space of the biological cell as a basic unit of life. As a criterion for life, containment "implies that a system must be inherently an individual unit, a function provided by biological membranes", and is given by the unity established as the equilibrium between complex "environmental stresses from the exterior as well as the pathogenic processes from the interior of the cell" (Hensel 2021).

Biological life forms are also recognized as having the quality of being 'alive' because they respond. Their responses are organized by an energy that appears as involuntary reactions to their milieu, whether defined by external environmental stimuli or internal need. The ability to respond is another frame that sets up a difference between interiority and exteriority of life. The frame of stimulus and response 'spaces' life.

The frame becomes an architectural limit idea which conditions the very possibility of life itself, even before, according to Bernard Caché, we can recognize the frame as an image (xi). The 
issue with life as a functionalist explanation is not the use of biology to explain the human being, but lies with the visuality of biological life in relation to human beings. Biological life can be seen; it is a Kantian a priori idea. It has a predetermined image whose characteristics are historically understood and admired, leading to the desire for mimicry to establish a visual correspondence between the processes of human material production and natural processes. However, the image of the biological life in such biomimicry arrives from one that which is already partitioned in a certain manner (away from the human, arguably by architecture since the Renaissance). The image of biological life is one based on a contained, captive organism reduced to its fundamental behaviours of survival.

What are the implications of this line of reasoning in response to biological life as a frame for contemporary architectural techniques and technologies, especially those that have arisen with the development of digital visualization and design capabilities? More specifically, how do we philosophically deal with the mimetic correspondence between biological life and architectural production as a quality whose frame primarily relies upon relations that are governed by a certain regime of visuality, when it is architecture that provides the frame which makes visible the qualities of that life in the first place? The rest of this paper traces a line through the complex field of framing in biomimicry, the implicit collapse of the space between the biological organism and its milieu, to argue particular digital techniques or computing technologies in architecture are not anterior to the concept of life and vice versa, but that the concept of biological life is something that is inseparable from the techniques and technologies in architecture, where the latter are themselves emergent in their grasping of, and being grasped by, the concept of life. It is more productive to see the concept of biological life as habit that can be cultivated, with a 'pedagogy' that can be developed.

\section{Captivation}

Biological life, having been defined in history through an architectural partitioning of space between inside and outside, provides the condition of captivation necessary for the identification and categorization of the organism. The conventional sense of captivation is the enclosure by architectural walls, as in 'captivity'. Captivation can alternatively be read as an inconspicuous (un)attentive comportment to the world, as in 'to be captivated by'. Giorgio Agamben, working inside Heidegger's idea of 'the open' in which human beings captivated by the world have the possibility of authentic thought, argues that human beings in fact become more animalized when they are captivated in or by the unconcealment of the world. The condition which reifies Agamben's reading of 'the open' is boredom (61). The experience, or more specifically the non-experience, of boredom results from suspension of conscious thought or circumspective comportment. Here existence is undifferentiated from the milieu. The world of captivation is close to an existence that matters no matter what comes, as it is life sharply cued into certain conditions in which the world is open to the organism as an unending horizon of events that pertain to basic biological activities such as eating and shelter. For humans, this occurs in the partitioned spaces where the architecture is inconspicuous where there is a suspension of self-consciousness, where the human can be naked or disclosed, and where it pursues its basic survival activities. This is the space of habits, or particular combinations of materiality, structure and movement which hold off conspicuous introspection towards a kind of releasement. This is quite possibly the space of the home, or the daily work environment. Here is where the human in captivation learns to be bored, and becomes biological, becomes animal. Life in captivation is therefore not related to consciousness or biological form per se, nor is this state of biological life a pathological or 'other' condition of the human. The definition of biological life that is of concern here is, as Catherine Ingraham puts it, radically outside, as unknowable, to humanness (86).

\section{Mimicry}

Captivation, as a space of biological survival, sees the collapse of difference between the milieu and the organism. In some animals, insects in the main, this pursuit of survival manifests as a repertoire of behavior related to mimicry, or morphogenetic transformations, where their forms mimic the surrounding environment. For example, stick and leaf insects evolve to be visually similar to their habitat, and the large eyes on butterfly wings develop in such as way to make the insect look like a bird. Natural mimicry is the limit state of the captivation of an animal by its milieu.

In his seminal essay "Mimicry and Legendary Psychasthenia", biologist and dissident surrealist Roger Caillois argues that the Darwinian evolutionary advantage of mimicry is on many 
occasions a fallacy (16-32). Leaf insects by their appearance as leaves increase the propensity of being cannibalized by their fellow insects; and stick insects by being sticks have the propensity of being snapped off as twigs or fed on by sparrows. Furthermore, mimicry does not serve survival because it works in the realm of the visual while hunting primarily works at the level of smell (Krauss 155). The evolutionary non-benefit of mimicry therefore overturns functionalist explanations of the animal and biological behavior. But yet, there is an undeniable primitive and overwhelming tendency to imitate - and this applies as much in the human realm as that of the animal; all we have to do is look down the history of architecture or art for the imitations of nature - with a belief in the efficacy of this imitation.

What is of interest to me in Caillois's work is that mimicry enacts a spatial condition, namely the collapse of the space of difference. Mimicry, as a visual act which relies upon similarity or likeness, puts pressure on the space of differentiation that subsists between things, between the biological organism (and in the current discussions of architectural practice, the human animal) and its milieu. Caillois compares the natural phenomena of mimicry and the psychiatric condition of psychasthenia, the loss of ego owing to a disturbance in the experience of space, whereby the ego no longer has a form because its difference from its milieu is dissolved by that experience of space. The ego has a lessened individuality so to speak as it sees itself as one point amongst many others, until it knows not where to place itself. This biological human is in dark space where there is no differentiation between its body and its surroundings.

Architectural theorists such as Ingraham in Architecture, Animal, Human: The Asymmetrical Condition and Elizabeth Grosz in Architecture from the Outside have used the condition of psychasthenia, largely through a reprise of Caillois's essay, to breach the separation of the Cartesian subject from its non-human milieu, or generally the inside-outside distinction, in architectural thinking. If we apply this thinking to the biomimicry implicit in some digital architectural practice, whether the resultant architectural forms mimic natural organismic behavior or structuration, or the use of parametric modeling which introduces design methods able to instrumentalize complex systems and control morphogenetic structurations; which in turn provide designers with the capacity to develop 'long chain' associations of geometric constructs, changes in behavior and procedural representations, and responsive materiality; and where editing and re-execution of design history is made possible; we are faced with a visuality in architecture that diminishes the perspectival relations between the viewer and the milieu in favour of a diffracted visuality. What I mean here is that the conditions of vision and perception may not be a possession of the human subject, but might in fact constitute the human subject, or dispossesses it. The human is dispossessed of its assumed centrality in vision. Instead its milieu pinions the human as a biological subject within its stare, or captivation. This dispossession, where the human gives itself over to its own blinding, and its primary existence is merely a spot within the complex scopic field, inscribes human life into the biological picture rather than being removed from it as the source of creation. We stand in a milieu we cannot place, that absolutely cannot be mastered by the logic of vision. Through captivation, the human is seen as immanent in, rather than sees, the milieu.

To me this is when the human moves closest to the quality of biological life. Such an existence associated with the collapse of space brings about a radically indeterminate comportment to the world. Life itself, the natural and the biological, is co-produced in architecture as material, processual and spatial. It is here that relations between form and content, thought and matter, organic and inorganic, the organism and its milieu, are reworked. Biological life becomes a concept that works like a generic category. It remains as having no accepted measure, but it nevertheless functions as an event site. As generic quality, the life can only be approached always and only as becoming-life. Life as concept and process in architectural production is therefore immanent to the forms it takes.

The revelation by the techniques and technologies in architectural production cannot therefore be anticipated, and is highly impersonal (it has less to do with the individual biological human, and more the non-individualistic or generic category of the biological). And in this way the newness in architectural production within the biological paradigm is both transcendental (as in trans-historical) and immanent (as in emergent in the event). This double fold forces knowledge to increase the anticipation of the full truth of life - a truth which never arrives - but allows architectural theory and practice, as Alain Badiou says of the politics of philosophy (29-31), to act with conviction and fidelity. 


\section{Pedagogy of a concept, habit formation}

Such a non-teleological and ontologically indeterminate framework treats biological life a 'concept' as described by Deleuze and Guattari. Life is a concept and not a proposition, because the truth of a proposition relies upon an outside state of affairs to which it refers, while the concept is internally organized whereby it is always already, and only, the partial interconnections with other concepts around it. Life as a concept has its own regions of visibility and effectuation, each with a series of techniques and technologies. Concepts are not created out of nothing; there is no genius-creator behind concepts, but their creation is immanent to a constant reaching out and being reached by other concepts. Deleuze and Guattari describe the internal consistency of concepts as follows:

"As fragmentary totalities, concepts are not even the pieces of a puzzle, for their irregular contours do not correspond to each other. They do form a wall, but it is a dry-stone wall, and everything holds together only along divergent lines" (23).

Concepts are therefore created by a self-positing. So, on one hand, the concept in its selfpositing is absolute and therefore ontological; on the other, it is relative in its creation and therefore has a pedagogy. What does it mean to have a 'pedagogy of a concept' in inherent in its creation? For a concept to live, it necessarily summons certain words, images, and structures. The choices of these material instantiations evoke a link to what Deleuze calls a 'philosophical taste'.

"The concept's baptism calls for a specifically philosophical taste that proceeds with violence or by insinuation and constitutes a philosophical language within language - not just a vocabulary but a syntax that attains the sublime or great beauty" (8).

For example in the biological paradigm, the qualities of life resonate within words such as 'emergence', 'evolution', and 'consistency'. These words then make up a whole way of speaking that is immanent to the concept of life; it is what the concept is. The concept's sole object is the inseparability of the components which constitute its consistency and through which it passes back and forth. The philosophical concept does not refer to the 'lived' by way of abstraction, but through its own creation it sets up an event which Deleuze and Guattari says "surveys the whole of the lived no less than every state of affairs" (33-34).

So how does the Deleuzo-Guattarian concept of the concept relate to the conditions made available by biological life as a concept in the techniques and technologies in digital architecture? Biological life as a concept gives life to strange beings, beings which matter if they fulfil with fidelity the scientific and design constraints set by the techniques and technologies to unfold the architectural problem to its fullest potential, a move which at the same time holds the risk of being monstrous, dangerous, and disastrous (Stengers 165). This relativity in the pedagogy of a concept means being in a debt we need to honour in relation to what makes one call up the concept in the first place. Science has given architecture the concepts of 'nature', 'animal', 'biological life'. Architectural philosophy needs to deal with the flights they induce, concepts they create and habits they disturb; not to justify, rationalise or interpret biological science in architecture, but to care that truth of the problem achieves the production of its own specific empowering means and obligations.

\section{Conclusion}

The biological paradigm in architecture does not merely provide formal concepts which are mimicked or appropriated by human designers, nor are the relations between human and biological beings made closer. The concept biological life is where human beings encounter a comportment to the world which it cannot anticipate, which plunges them into an immanent relation with specific techniques and technologies, their transfers and transformations, whereupon life itself emerges. In this way, the paper is interested in the space of the subject and the space of architectural design, not in and of themselves, but because they are coemergent.

In biological life is a pragmatic concern of whether a philosophical concept works, or matters, regardless whether it fits within a universal ontology or metaphysics. Life, which subscribes to the 'pedagogy of a concept', is necessarily a non-consensual and divergent convention. Herein lies a new paradigm of ethico-aesthetics, whereby life becomes a pragmatically functioning but constantly diverging event which serves nothing more than to empower new habits; habits that are self-jeopardising and highly idiosyncratic, to ensure further concept creation. 


\section{References}

Agamben, Giorgio. Homo Sacer: Sovereign Power and Bare Life. Daniel Heller-Roazen trans. Stanford: Stanford University Press, 1998.

Agamben, Giorgio. The Open. Kevin Attell trans. Stanford: Stanford University, 2004.

Badiou, Alain. Infinite Thought: Truth and the Return of Philosophy. Oliver Feltham and Justin Clemens eds. and trans. New York: Continuum, 2003.

Caché, Bernard. Earth Moves: The Furnishing of Territories. Massachusetts: MIT Press, 1995.

Caillois, Roger and John Shepley. "Mimicry and Legendary Psychasthenia." October 31 (Winter 1984): 16-32.

Deleuze, Gilles and Felix Guattari. What is Philosophy? Hugh Tomlinson and Grant Burchell trans. New York: Columbia University Press, 1994.

Hensel, Michael. "(Synthetic) Life Architectures: Ramifications and Potentials of a Literal Biological Paradigm for Architectural Design." Michael Hansel, Achim Menges and Michael Weinstock eds. Techniques and Technologies in Morphogenetic Design, Architectural Design London: Wiley-Academy, March/April 2006.

Ingraham, Catherine. Architecture, Animal, Human: The Asymmetrical Condition. London: Routledge, 2006.

Grosz, Elizabeth. Architecture from the Outside: Essays on Virtual and Real Space. Cambridge: MIT Press, 2001.

Krauss, Rosalind. The Optical Unconscious. Cambridge: MIT Press, 1993.

Stengers, Isabelle. "Deleuze and Guattari's Last Enigmatic Message." Angelaki 10, 2 (2005).

Wigley, Mark. "The Architectural Displacement of Philosophy." The Pratt Journal of Architecture. No. 2 (1988). 